\title{
Foundations Of Service Science Management And Business
}

\author{
Harry Katzan, Jr., Savannah State University, USA
}

\begin{abstract}
This paper continues with the conspectus of Service Science for academicians and practitioners. It follows the previous paper, entitled Foundations of Service Science: Concepts and Facilities, with the express purpose of defining the scope of the discipline. A thriving flexible service economy has emerged through globalization and digitization, and as a direct result, the modern enterprise has a dynamically changing boundary based on a portfolio of services obtained through make, buy, or rent decisions. Through the application of information and communications technology (ICT), many organizations have adjusted everyday operations enabling them to go through a transformational process to achieve revenue growth by being able to respond more quickly to changing market conditions and by being more effective and efficient in the application of services. The viewpoint taken here is that service management and modern business usually employ a complex computer infrastructure, but their domain is by no means restricted to computer-based services.
\end{abstract}

Keywords: Service management, IT services, service strategy, value net, service business, operations framework, service governance.

\section{ENTERPRISE SERVICE CONCEPTS}

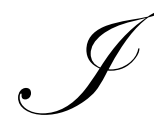
$\mathrm{n}$ the multifaceted domain of services, management and business are intertwined. An enterprise, taken in this paper to be a business, government entity, or educational organization, simultaneously manages its own services and services provided to clients by adopting the role of service provider or service client. In short, an enterprise is likely to be a provider and a user of services. In fact, many internal services are managed as a business and in some instances evolve into external service providers - all with the same or similar functional deployments. So the fine line of separation between management and business is nonexistent, and that phenomenon is clearly evident in the following sections. Any conceptual overlapping of the subject tends to enforce the contention that the two subjects support each other.

\section{SERVICE MANAGEMENT}

Historically, the focus of service management has been on the application of traditional management concepts to enterprise processes that primarily involve services. Typical business examples are banking and health care that have greatly benefited from the application of scientific principles to everyday operations. Two common applications are the use of waiting-line methods for the front office and process scheduling techniques for the back office. Through the application of information and communications technology (ICT), many organizations have adjusted everyday operations enabling them to go through a transformational process to achieve revenue growth by being able to respond more quickly to changing market conditions and by being more effective and efficient in the application of services. This section describes modern services management. The viewpoint taken here is that services management employs computer concepts, but its domain is by no means restricted to computer-based services and includes just about any service that a person can imagine. 


\section{Service Management Concepts}

There are three forces operating in the sphere of service processes. The first is the use of ICT enablement in providing revenue growth, efficiency, and effectiveness for traditional and enhanced services, as well as for conventional business processes. This subject is commonly referred to as information systems. The second is the consulting services domain that provides IT services to external organizations. The third is the use of ICT to manage information systems and services, which is a field of endeavor known as IT Services Management. Briefly said, it is the use of computers to manage the enterprise and also to manage itself.

\section{Domain Of Service Management}

Many people feel that what you see in the world depends on the lens through which you are looking. So if you adopt a service-centric point of view, most socially-developed phenomena can be viewed as services. ${ }^{1}$ It follows that if we are going to manage services, we should at least consider to whom services are applied and how the service delivery is achieved.

We are going to focus on an organizational setting consisting of people and everyday operational units. The service provider, in this instance, is a person acting in a service capacity or a group of persons, including support facilities, that has adopted a role of a service provider. The service object is another person or operational unit, usually referred to as a business unit. In the latter case, the service object need not be part of the same organization as the service provider. Some examples of service relationships are: (1) an accounting department in a manufacturing company; (2) a computer support person in an academic department; (3) a consulting group that services external customers; (4) an IT department that serves several business units in the same organization; and of course (5) a service professional serving several clients.

There are at least three different types of service arrangements: ${ }^{2}$

Type I: The service provider delivers services to only one service object.

Type II: The service provider delivers services to more than one service object in the same organization.

Type III: The service provider delivers services to one or more service objects in external organizations.

Once a provider type is identified, in a particular instance, the next step is to determine who pays for the service and specifically how that support is organized. This process is known as service provisioning.

The internal processes of effective service management go through a cyclic process, known as the service lifecycle that includes service strategy, service design, service transition, service operation, and continual service improvement. The use of the methodology presented in this section is known as best practices. Most service organizations and all IT organizations would perform better if they adopted a set of best practices, and clearly, many of them do.

\section{Service As A Business}

The notion of service has its origin in ancient times and was understood to mean "one person doing something for another." With the advent of civilization and industrialization, the definition of service was implicitly extended to encompass "one person doing something for an organization," usually in the form of employment. At this stage, specialization and entrepreneurship kicked in with all of their rights and privileges resulting in what we now recognize as the service organization.

Specialization has its roots in process efficiency, but has definite social overtones. Some jobs are more lucrative and have more prestige, and for a variety of reasons, people can do some tasks better than others.

\footnotetext{
${ }^{1}$ Some service scientists have adopted the viewpoint that all products are actually services. When you buy a car, for example, you are buying the service the car provides. Clearly, some services of this nature are intangible.

${ }^{2}$ A good reference to this topic is An Introductory Overview of ITIL® V3, The IT Service Management Forum, itSMF, 2007.
} 
Specialization is not limited to individuals but applies to organizations and groups within organizations, as well. Specialization is commonplace, not only in service organizations. In conventional business processes, such as a sales group, certain tasks are performed more expeditiously by a single individual or group, as with credit checking, when the task is performed repeatedly. The degree of specialization needed in a service process is related to the amount of repeatability. Most production and service chains divide the process into individual tasks that are performed by a single unit, taken here to be a person, group, or machine, such that efficiency and effectiveness is achieved through specialization.

Innovation flourishes in a receptive service environment, so that effective service groups are commonly at odds with their parent organization. Service spin offs have resulted in a thriving service economy through entrepreneurship and innovation. Accordingly, it is important to recognize that service is a business, and that the principles given here apply equally well to internal and external service organizations.

\section{Service Componentization}

Services are ubiquitous so practically everyone knows what one is. Well, maybe they can't exactly define it, but they recognize one when they see or experience it. What most people don't think about, unless they have to, is that a service is a process. Beneath the surface, there is usually a collection of activities to support that process. The activities are organized into components.

A component is an organizational entity for instantiating services. Some components provide more than one service and some services are comprised of more that one component. The operation of a simple restaurant is used to clarify the concept of componentization. ${ }^{3}$

We go to a restaurant for a meal. The meal is the service we are seeking. We grab a table, look at the menu, and give our order to a waiter or waitress. Subsequently, the meal is delivered. We consume the meal, pay the tab, and leave. In our interaction with the waiter or waitress, we exchange information, so in a very general sense, we co-produce the service event, although we do not experience the meal preparation. This is not a pure service, since the food is a product. However, the service part of the meal is a service.

On the other hand, we all know that the restaurant is a collection of interacting components that provide a meal service to one or more guests. The components of the restaurant are the server (i.e., the waiter or waitress), the kitchen (that prepares the food), a cleaning component, a foodordering component, an accounting component, a facility-management component, and a restaurant management component that orchestrates the services supplied by the components. The service orchestration, which is an explicit or implicit specification of the interactions between components, is a necessary element in the design of a managed service system.

Collectively, the arrangements of components that make up a service offering constitute its architecture. In service architecture, some components are internal persons or units, some components are outsourced, and some components are business partners. One aspect of service management is the choreography of components in a specific business process - that is, how information or tasks is passed between components without explicit direction.

Another important aspect of service management is keeping track of the components and their attributes. When a service organization gets complicated, a service repository is required to keep track of the services that are provided by each component and what components are needed for a particular service process. Usually, a computer database is used. From a strategic viewpoint, a component is an asset that must be managed just as any other asset.

\footnotetext{
${ }^{3}$ Adapted from Hurwitz, Bloor, Baroudi, and Kaufman (2007).
} 


\section{IT Services Sourcing}

There are several aspects of IT services that can vary between organizations. Examples are commonplace: computer operations, network management, hardware and software acquisition, system analysis and design, software design, software development, information systems integration, and call center and help desk operation and management. This is a representative set of tasks necessary for sustaining an IT services organization. You can do them yourself; you can have another business entity help you do them; or you can have a business entity do them for you. In the latter two cases, the business process is known as IT service outsourcing.

Most IT services reflect an underlying set of IT assets, such as hardware, software, users, and systems. The IT services organization has three possible roles regarding these assets: develop or acquire, operate, and manage. For each of the IT assets, role adoption can differ. For example, hardware can be acquired internally and operated by an outside contractor.

The entity that provides the service, that is, the external business unit, need not be an independent business entity in a foreign country. It can be a separate business unit in the same enterprise, located locally, in the same country, or offshore. Alternately, it can be an independent professional services business entity in the same country - a service usually regarded as IT consulting. In many cases, however, the organization providing the outsourced service $i s$, in fact, an independent business entity operating out of and located in a foreign country.

\section{IT Services Management}

It would seem that a person's view of IT services management would be different, depending on whether your organization is the service provider or the service client, and indeed, it is. The common denominator between the various perspectives is the set of common issues that business and IT managers have to deal with, some of which are strategic planning, IT and business alignment, measurement and analysis, costs and investment, business partners and relationships, sourcing, continuous improvement, and governance. The issues are repetitive, recurring, and ongoing, and constitute a service lifecycle. The elements of the lifecycle are generic and do not necessarily apply to all service systems. Differences lie in the adoption and deployment of the lifecycle elements.

At the heart of IT services management is a set of tasks that involve "keeping track of things," and there are a lot of things to keep track of. We will call them service elements. Some of the service elements are obvious, such as users, hardware, software, network components, office facilities, and configurations. There are other service elements, mostly related to enterprise operations that can offer a challenge, such as categorization of services, to whom those services are supplied or alternately, from whom those services are obtained, contractors, outsourced projects, outsourcers, and business partners. A service directory is needed for this type of record keeping. Lastly, with regard to business alignment and service operations, there is a whole host of service operational elements that collectively possess business value that should not be ignored. Three of many such service operational elements are incident management, problem management, and change management. It is through the integration of service operational elements that an enterprise can achieve significant business value. The subject is covered in later sections.

\section{Elements Of The Service Lifecycle}

The service lifecycle consists of five important elements, listed as follows: Service Strategy, Service Design, Service Transition, Service Operation, and Continuous Improvement. This sequence represents the waterfall model that suggests how the requirements process goes from strategy to continuous improvement, implementing a feedback process as required. Each element of the service lifecycle is considered separately.

\section{Service Strategy}

The most important element in the service lifecycle is service strategy. Successful service operations are not sustainable over long periods, because of environmental turbulence affecting resources, competition, and 
requirements. Accordingly, a service strategy is needed. A strategy is a long term plan, based on objectives, that allows an organization to adapt to changing conditions.

Since service is a client based endeavor, it is necessary that a service delivers perceptible value. A service strategy based on client needs is necessary for successful service operations. A service strategy, recorded in $\mathrm{s}$ strategy document, should reflect whether the strategy is intended for a provider or a client. How an organization uses a service strategy is an individual matter. A service document should reflect major items, such as whether services are managed internally or outsourced, who the key collaborators are, and what service management functions, such as problem and incident management functions, are needed.

\section{Service Design}

Service design refers to the synthesis of services to satisfy enterprise objectives. This stage has general applicability, even though it appears, on the surface to reflect IT services. Service design incorporates service architecture, processes, policies, and requisite documentation. Even though the service strategy phase identifies services, the service design phase is where they are established to satisfy business objectives. Even though a computer-based service is developed offshore, it is usually developed by the parent organization during this phase. Risks, quality, measurement, and infrastructure requirements are specified in this stage. Also, this stage involves capacity management, availability management, security management, and key organizational responsibilities.

\section{Service Transition}

Service transition concerns the implementation of services in the sense of putting them into a production environment. As such, service transition is an organizational bridge between the design and the operations stages. In many instances, the service transition phase involves a change to existing services involving limited functionality and operational procedures. As such, a service transition requires the establishing of or adhering to a formal policy for the implementation of required changes and the development of a framework for the integration of the changes. When additional training and help desk support is needed, it is established in the service transition stage, which may also include system validation and testing.

\section{Service Operation}

The function of the service operation stage is to manage and deliver the services established in the design stage. Business value to the enterprise is delivered in the operation phase, and event monitoring is of prime importance. A service event is a change of state during the delivery of a service that requires attention, such as an unplanned interruption of service. Two service management functions are commonly involved: incident management and problem management. Incident management is primarily concerned with resolving the situation and getting the system back up and running. Problem management focuses on determining the root cause of an event and interfaces with change management to insure that the problem is not a recurrent event.

\section{Continuous Improvement}

Continuous improvement, or more properly, Continuous Service Improvement, refers to the process of maintaining value to the enterprise of a service or set of services. Practically all enterprises, subscribing to services, engage in continuous improvement to some degree, to protect their investment. As suggested in Figure 5.2, the output of continuous improvement, known as Service Reporting, feeds back into the other four stages, on an as needed basis, constituting the service lifecycle.

This stage consists of seven steps, listed as follows ${ }^{4}$ :

1. $\quad$ Define what you should measure

2. $\quad$ Define what you can measure

\footnotetext{
${ }^{4}$ The 7-step improvement process is defined in the IT Infrastructure Library (ITIL version 3) specification.
} 
3. $\quad$ Gather the data

4. $\quad$ Process the data

5. $\quad$ Analyze the data

6. $\quad$ Report the information

7. Implement corrective action

Continuous improvement is an excellent management tool as it suggests a means of prioritizing ongoing strategy and design activities.

\section{EVOLUTION OF SERVICE MANAGEMENT}

This section covers three topics relevant to effective service management: value nets, the pull model, and E-services. The subject of service management is constantly evolving, because the modern enterprise has a dynamically changing boundary based on a diverse portfolio of services.

\section{Value Nets}

A value $n e t^{5}$ is a means of capturing business value from the integration of strategy, process, workforce, and technology. Business value is created by shifting from the traditional value-chain model to the value-net model in service systems. In the value-chain model, an organization creates value by adding elements to the finished product at each stage of a production process. In a general sense, raw materials are converted to value in a step-by-step production line. The modern competitive environment, however, requires faster turnaround time and more choices, especially with regard to service management.

Successful enterprises currently use value nets in which suppliers and business partners interoperate through information over networks on a demand basis. The relationships between organization, suppliers, business partners, and customers are dynamic and adjust to changing requirements. Value nets are efficient because of the real time combination of services supplied by the key participants - the business, buyers, suppliers, and business partners.

\section{The Pull Model For Service Agility}

Hagel and Brown ${ }^{6}$ have identified the pull model as a means of mobilizing business resources for the upcoming generation of business activities based on mass communications and the Internet. The characteristics of the pull model are succinctly summarized in the following sentence from the Hagel/Brown web report. "Rather than 'push,' this new approach focuses on 'pull' - creating platforms that help people to mobilize appropriate resources when the need arises." Push models are "script oriented" and thrive in stable environments with little uncertainty. Forecasting, as in demand forecasting, is key in push environments and allow high levels of efficiency to be developed in business processes. Pull models are more amenable to uncertain business conditions that require compressed development times for new goods and services. The pull model represents service architecture at the enterprise level, and could properly be viewed as an enterprise service architecture.

The pull model is a profound concept, since most services are client initiated.

\section{E-Services}

Every year, businesses spend millions of dollars on their IT infrastructure consisting of hardware, system software, applications, networks, people, and other organizational assets. With "on demand" computing, they can plug into the wall, figuratively, speaking, and only pay for the IT services they use. The concept is called utility computing that is accessed as are most public utilities. We are going to refer to the utility computing concept as $E$ services. An E-service utility is a viable option for the provisioning of computing services.

\footnotetext{
${ }^{5}$ See Cherbakov, L., et al, "Impact of service orientation at the business level" in the selected reading.

${ }^{6}$ See Hagel, J. and J.S. Brown, From Push to Pull: Emerging Models for Mobilizing Resources in the selected reading.
} 
The concept of E-services is the packaging of computer services as a metered facility without up-front costs for IT infrastructure and is commonly used for large-scale computations or peak demands. In the current view of things, an E-services utility is network based and is dependant upon the Internet as a transport mechanism. In recent years, computing has become the operational medium for business, government, and education and part of everyday life for most people. As with electric utilities, computing utilities have evolved from being a luxury to an everyday necessity.

An E-service utility is characterized by four key factors: ${ }^{7}$ necessity, reliability, usability, and scalability. Necessity refers to the idea that a preponderance of users depend on the utility to satisfy everyday needs. Reliability refers to the expectation that the utility will be available when the user requires it. Usability refers to the requirement that the utility is easy and convenience to use - regardless of the complexity of the underlying infrastructure. Scalability refers to the fact that the utility has sufficient capacity to allow the users to experience the benefits of an expandable utility that provides economy of scale. Certainly, modern Internet facilities for search operations that engage thousands of servers satisfy these characteristics.

The notion of "paying for what one uses" is a compelling argument for using E-services for special or all computing needs. However, the proof of the pudding may in fact be in the details. The key question is whether the service should be based on a metered model or a subscription model. With the metered model, the usage is easily measured, monitored, and verified and lends itself to managerial control on the part of the user. In addition, metering can be applied to differing levels of service. With the subscription model, usage is difficult to control and monitor and its adoption is favored by managers more concerned with convenience than with resource control.

For example, water and electricity service commonly use metered service while the plain ordinarily telephone system "usually" provides subscription service for local service and metered service for long distance. In the area of computer networks, broadband cable and telephone digital-subscriber line (DSL) rates are normally based on the subscription model. With cable TV, on the other hand, there are usually differing levels of subscription service along with "pay per view" for special services.

One can readily conceptualize a scheme for a typical E-service customer - nominally assumed to be a small-to-medium-sized business. Office services, such as word and spreadsheet processing, could be subscriptionbased service and special applications, such as integrated enterprise systems, would be metered service.

The difference between application services and multi-tenant services may very well be the deciding factor in determining whether metered or subscriber service is the way to go. With multi-tenant service, several clients may share the same software with separate data - as in the case of office processing. With application service, the service provider supplies one instance of the software per client, thereby lending itself to a form of metered service.

\section{SERVICE BUSINESS CONCEPTS}

Several important factors have contributed to the new business model based on services. The complexity of the modern work environment is perhaps the key factor as well as the changing demands of a networked economy. The increased level of worldwide incomes has added to the desire for enhanced business and social services. The dependence on information and communications technology (ICT) has been an enabler of the complexity and growth of services by facilitating the connection between suppliers and consumers of services.

\section{Business Model}

A business model is a representation of a business emphasizing its purpose, strategies, organization and operational practices, and capabilities. It typically covers the following: core capabilities, partner network, value proposition, customer base, distribution methods, cost structure, and revenue base. ${ }^{8}$ One of the functions of a business's organization and operational structures is to translate the business model into an objective reality.

\footnotetext{
${ }^{7}$ See Rappa (2004).

${ }^{8}$ For a complete list, see the Wiki article on business models.
} 
The point of view taken here is that an operational service model is a business model.

\section{Strategy And Mission}

A strategy has been defined as "A long term plan of action designed to achieve a particular goal," and governance as "The set of processes, customs, policies, laws, and institutions affecting the way an endeavor is directed, administered, or controlled." The two subjects command our attention, because much of the economy and workforce are engaged in services; but, as we have alluded to before, we seem to know the least about what we do the most.

The basic tenet underlying strategy is that a principal entity desires to accomplish something worthwhile called a mission. A mission is required so the entity, be it a business, firm, government agency, educational unit, or person, knows where it is going, and a strategy is needed so it knows how to get there. The mission is a service participant's goal, and the strategy is the roadmap for achieving that goal. A strategy is a plan of action.

\section{Service Ecosystem Characteristics}

Before the revolution in ICT services, the exchange of information was a supporting element in most aspects of economic activity. Through advanced technology, information is now an important component in the value proposition of most services.

The modern enterprise can now exploit informational resources on a demand basis from remote locations and without necessarily owning them. Moreover, the facilities necessary to sustain those resources may be shared, creating innovative opportunities for service provisioning.

Through web sites, mobile computing, and kiosks, self-service channels are currently available to support informational interchange. Business functions, such as billing, payments, ordering and order processing, reservations, online service support, and information management, are currently available without regard to time or distance.

Through innovation and entrepreneurship, new business opportunities are available on an on-demand basis, frequently constructed from existing services.

\section{Strategic Assets}

A strategic asset is a resource that provides the basis for core competencies, economic benefit, and competitive advantage, thereby enabling a service business to provide distinctive service in the marketplace. Because services are labor intensive, investments in people, processes, knowledge, and infrastructure are directly analogous to investments in resources for production and distribution in capital intensive businesses.

Strategic assets permit a service enterprise to achieve a competitive advantage through service differentiation, cost advantage, and superior customer response. Service differentiation involves providing a high degree of uniqueness in the service experience and also in the quality of service provided. Cost advantage refers to efficiency in the use of facilities, as in an airline terminal, and with 24/7 operations to maximize the use of infrastructure. Customer response involves flexible, reliable, and timely solutions to customer requirements.

\section{Service Context}

A service context supports the efficacy of service provisioning. The development of a service context involves the asking of tough questions to examine the strategic goal and objectives of a service organization in order

\footnotetext{
${ }^{9}$ Adapted from the Wikipedia articles on strategy and corporate governance.
} 
to identify and establish a service portfolio. Here are some questions a service organization might want to ${ }^{10}$ ask of itself:

- What services should we offer?

- To whom should the services be offered?

- $\quad$ How do we achieve competitive advantage?

- What is our customer's value proposition?

- How do we establish value for our stakeholders?

- How do we define service quality?

- How do we allocate strategic assets to our service portfolios?

- What are the bottlenecks to growth and effective service provisioning?

The questions apply in differing degrees to whether services are provisioned for one organization (or department), one of more units within the same parent organization, or to units in different organizations. Moreover, the services apply within the following contexts: do them yourself, another business entity helps you do them, and have another business entity do them for you.

\section{Service Perspective}

Every reasonable business model demands a context and the one presented here is no exception. Our service model is based on a service management concept for providing value to customers in the form of capabilities that translate resources into valuable services.

The objective of service provisioning - regardless of whether the service involves people processing, possession processing, or information processing - is to provide value to customers through an intrinsic knowledge of customer needs obtained by preparation, analysis, usage patterns, and the application of best practices. Within this perspective, a service may be alternately defined as a means of delivering value to customers by facilitating outcomes customers want to achieve without the ownership of specific costs and risks. ${ }^{11}$

\section{SERVICE FACTORS}

Three factors determine the need for services and the realization of those services. They are: value, flexibility and control, and risk. With regard to the value factor, it is not just value, per se, but value versus cost. When costs are reduced through internal or external outsourcing, for example, there should be concern over whether the value of the service to the client is the same as or greater than before the outsourcing. Using resources and capability as inputs to a service, is the resulting value to the client commensurate with the cost? Similarly, when internal or external outsourcing is implemented, there is concern over operational flexibility and management control. Some organizations have experienced the "tail wagging the dog" syndrome and have had to bring major services, such as IT outsourcing, back into the parent organization. It is very difficult to modify strong service level agreements, so the parent organization is effectively constrained by the very services that were supposed to provide them with business agility. Also, successful outsourcing, in some instances, has been diluted through mergers and acquisition, whereby competing services have been assimilated into a parent organization, effectively comprising the original benefits. Lastly, there is risk inherent in relying on services, even though there is a customary risk to be expected in everyday affairs. The uncertainty in the application of service level agreements works contrary to the expectation on the part of clients to receive a positive effect with the utilization of assets.

Injecting a bit of reality into the analysis, there is always the headache factor. The possibility always exists that outsourcing or calling in a consultant, is a means of relieving an organizational headache - regardless of the cost. Similarly, living with a third party in the form of outsourcing may be too much for some organizations to handle.

\footnotetext{
${ }^{10}$ Adapted from ITIL, p.9.

${ }^{11}$ See Clark (2007), p.5.
} 


\section{Service Creationism}

In most views of service theory, there would appear to be service creationist forces at work. Through some unknown process, an enterprise comes to life and ostensibly needs service of some kind. ${ }^{12}$ A service organization enters the scene and identifies certain processes associated with the enterprise that it can use to make a profit. It's clear that the target enterprise is the service client, and the service organization is the service provider. The activity on the part of the provider that identifies candidate processes for the proposed benefit of the client is sometimes called service innovation. Usually, service innovation amounts to very little more than an elementary form of observational research. ${ }^{13}$ In general, however, the tasks involved with creating and sustaining a service business usually constitute a rational process. The provider may possess superior capability, as is commonly the case with an IT consulting company that provides a variety of services to less experienced clients who choose to take advantage of the opportunity. The client's resources may be inadequate to effectively perform a particular set of tasks, as in the case of an enterprise that doesn't possess the needed people or technology to solve a particular problem or venture into a new area of endeavor. The client, in either of the cases, may choose to focus on core competency. In this instance, a core competency is a set of activities that affect the mission of the client. The use of services may be purely economic, which is usually the basis for most outsourcing.

Service creationism represents a provider-side view of service provisioning.

\section{Service Evolutionism}

On the other hand, a service evolutionist might view the subject of service acquisition in a different manner. With client-side service provisioning, the process of obtaining and deploying services evolves through several identifiable stages of organizational dynamics, based on the three factors presented above, namely value, flexibility, and risk.

Most enterprise processes are comprised of two kinds of activities: core functionality and supporting functionality. In a bank loan department, for example, the lending function is core, and credit checking is supporting. Similarly, in a pension writing department, the synthesis of a pension plan is core, and the back-office computer operations are supplementary. When multiple departments demand the same services, it is a common management decision to combine the service operations and in the process, possibly enhance the level of service. "Kick it up a notch" is the usual justification. This is the first stage, referred to here as the service recognition stage.

At this point the emphasis changes from operating a service to using a service on the part of the core departments. The core department is avoiding the risks and costs associated with the supplementary function, since service costs are shared. Let us call this the risk/cost avoidance stage.

After the need for non-core services is realized and instantiated, there is a universal tendency to reduce costs - because after all, the services are not core to the mission of the organization - or endeavor to make a profit on the service operation. A decision can be taken at this point to spin off the service department as a self-standing internal or external organization, or outsource the total operation to an outside service firm. It would appear that this is either the spin off stage or the outsource stage, as the case may be.

There are additional considerations, based on infrastructure and management control. Here are some options:

- $\quad$ Outsource the total operation, including infrastructure, people, and management control

- $\quad$ Retain infrastructure and management control and outsource the people and operations

- $\quad$ Retain infrastructure, management control, and operations and outsource the people

\footnotetext{
${ }^{12}$ An enterprise for this discussion is a business organization, a governmental department or agency, an educational unit, or almost any other form of profit-or-non-profit socially constructed organization.

${ }^{13}$ At this point, we are only considering service innovation. Product innovation involves other considerations, although we can easily make the case that all products are actually services.
} 
- $\quad$ Outsource certain tasks within any of the above options

Task-oriented outsourcing is perhaps the end-game in the relationship between enterprise dynamics and service science. It is commonplace in modern business to have professional and technical tasks, such as engineering, software development, and design, outsourced to specialist firms in much the same way that architectural services have existed for many years.

Service evolutionism represents a client-side view of service provisioning.

\section{SERVICE UNDERPINNINGS}

A service business is a collection of organizational assets that provide value to clients in the form of services by exploiting inherent capability on two levels: the client level and the provider level. Effective service provisioning permits the client to focus on core competencies.

\section{Value Creation}

The value of a service is determined by a client's expectation of service and the client's perception of the service that is experienced. Expectations are developed by word of mouth, personal needs, and past experience. The service that is delivered is a complex combination of five attributes: reliability, responsiveness, assurance, empathy, and tangibles. Reliability refers to the consistency of service. Responsiveness reflects the perception that the provider is willing to provide service. Assurance is a measure of the competence of the service provider. Empathy is a reflection of the personal attention afforded to clients. Tangibles refers to the infrastructure as it is related to the service experience. The five attributes of service quality reflect a traditional setting and do not take into account the complications associated with technology driven service provisioning.

To this important list, we are going to add availability, capacity, continuity, and security.

\section{Availability, Capacity, Continuity, Security, and Risk}

Availability reflects the degree to which services are available for use by clients under terms and conditions agreed upon in a service-level agreement. Clearly, a service is available only if the client can take advantage of it. Accessibility and expectations are major considerations from the user's perspective. The method of access should be made explicit in the service-level agreement and the user's expectations should be managed by the client. ${ }^{14}$

Capacity is the ability of the service and the service provider to support the requisite level of business activity of the client. Demand for service must be available within a specified range and the service provider must be able to supply service provisioning during peak periods in a shared environment.

Continuity refers to the ability on the part of the service provider to support capacity during disruptive and catastrophic events. Continued service is not the only consideration. Alternate and backup facilities in the form of services must be in the service landscape.

Security refers to controls to assure that client assets will be safe from intrusion, disclosure, and physical destruction. Security refers to operational security and to the physical safeguard of client assets.

Availability, capacity, continuity, and security collectively determine the client's risk in acquiring services and assist in differentiating between service providers. When comparing the cost and value of services, risk should be factored into the equation.

\footnotetext{
${ }^{14}$ The use of the terms client and user is intentional. Using the principal/agent model, the client is the principal and the user is the agent.
} 


\section{Service Assets}

Engaging in a business service would appear to be quite straightforward on the surface but is actually a complex arrangement of business units, service units, services that connect the two, and provider types. The abstract term business units refer to the provider assets that give value to the client when applied. Similarly, service assets refer to the functions that the provider can perform. It follows that a business service is a mapping between the provider and the client, in much the same way that we ordinarily conceptualize the physician/patient relationship.

\section{Service Portfolio}

A service portfolio is a conceptual collection or list of services. Use of the term is intended to be analogous to a financial portfolio of investment instruments. However, there are major differences depending upon the raison d'etre of the portfolio.

A financial portfolio is ordinarily thought to be a collection of assets synthesized so that when the value of one asset goes down, another goes up. This is a bit of a simplification, but it's the idea that counts. The best case is when the value of all of the assets goes up, and the worst case is when the value of all of the assets goes down. Normal life is somewhere in between. With a service portfolio, there shouldn't be a downside, but some service firms do some things better than others.

With services, the raison d'etre of the portfolio depends on whether you are talking to a provider or a client. A provider portfolio might be a simple list of services - something an accounting firm might have as part of their marketing collateral. An IT consulting business, for example, could list items such as strategy formulation, service programming, and operations management.

From the client perspective, however, a service portfolio in indispensable, because it provides a central source of services agreed to in conjunction with the service provider, along with terms, conditions, and service metrics. A related concern is a database of potential suppliers of services.

\section{SERVICE OPERATIONS FRAMEWORK}

An operations framework is a set of service management functions (SMFs) established as best practices that assist in providing business value to a client. They should be organized and staffed by internal and external providers involved in IT-based or non-IT-based service operations. The service functions definitely have an IT flavor to them but apply to all provisioning in the services domain. Collectively, the SMFs agree with the ITIL compendium of best practices ${ }^{15}$. Each of the generic SMFs is briefly summarized.

\section{Service-Level Management}

A service-level agreement (SLA) is a formal and signed agreement between the service provider organization and the business unit to document expectations and requirements of a service delivered to the business unit from the service provider. The agreement aligns business needs with delivery of services and facilitates delivery of solutions to business requirements at acceptable cost. It involves a definition of requirements, an agreement on specifications, operations management expectations, and a review clause. The tasks include the creation of a service catalog, the development of internal procedures, the ability to monitor and respond to operational conditions, and the ability to perform regular service-level reviews. The service catalog delineates the priority of service-level tasks, the expected effect on employees, a description of users, a listing and description of service assets, and the organization's business partners and suppliers. Service-level monitoring is a key issue. The major service metrics are availability, responsiveness, performance, integrity and accuracy, and security incidents. In order to perform the service-level monitoring, the following steps are required: the identification and criteria for

\footnotetext{
15 ITIL stands for Information Technology Infrastructure Library. It is a set of best practices for IT Services Management (ITSM).
} 
monitoring, establishing thresholds, the definition of alert, the specification of alert management, and essential response definition.

Service-level determination and management is the key element in a service package.

\section{Availability Management}

Availability management is the service management function that insures that a given service consistently and effectively delivers the level of support required by the customer. Continuity of service is the key objective. The usual risks to availability relate to technology, business processes, operational procedures, and human error. Countermeasures that have proven to be enhance availability are testing of business processes, effective release procedures, and employee training. The areas most affected by availability issues are the implementation of new IT services, critical business functions, supplier behavior, and internal organizational factors, such as policies, procedures, and tools.

\section{Capacity Management}

Capacity management is the service management function that optimizes the capability of the service infrastructure and supporting organization to deliver the required level of customer service in the established time domain. Capability of service is the key objective. This SMF is most affected by people, infrastructure, and technology.

\section{Service-Desk Management}

The service desk ia a single point of contact for customers and service technicians with the intent of delivering responsive solutions to service needs. The major service desk functions are to handle single incidents and individual service requests. Service desk scheduling has historically been a concern and the current trend is to have self-managed teams that utilize service triads or peak period scheduling. A triad consists of a three person team, with two people on and one off at any time.

\section{Incident Management}

The objective of incident management is to detect events that disrupt or prevent execution of critical or normal IT services, and to respond to those events with methods of restoring normal services a quickly as possible. An incident is any event that is not part of the standard operation of a business process that causes, or may cause, an interruption to, or reduction in, the quality of service. In this context, a problem is the root cause of an incident; a solution is a method for resolving an incident or problem that resolves the underlying cause; and a workaround is a means of restoring a specific incident without resolving the underlying cause.

\section{Problem Management}

The objective of problem management is to investigate and analyze the root causes of incidents and initiate changes to service assets to resolve the underlying problem. The key function of problem management is to reduce the impact of incidents, problems, and errors on the organization by applying methods of root cause and trend analysis.

\section{Change Management}

The objective of change management is to provide a formal process for introducing changes to the service environment with a minimal amount of disruption to normal service operations while insuring the integrity of critical business functions. Change management preferably goes through several distinct steps: change initiation, change request, change classification, change authorization, release management, and review by a change board. 


\section{Relationship Of Key Processes}

Incident management is focused on restoring normal service and identifies resolution actions; problem management is focused on the identification and resolution of underlying problems and their root causes; and change management deploys changes developed by incident or problem management.

\section{Directory-Services Management}

The service directory is a database of service assets. Directory services is essentially a database from which users can obtain information on service assets through a secure and organized process that is accessible through appropriate information and communications technology (ICT) facilities. The major directory service functions are to record change events, describe connectivity, track service objects, and identify assets in the service landscape.

\section{GOVERNANCE}

A typical organization has a group of stakeholders who have something to gain if the organization is successful and something to lose if the organization is not successful. The gain could be financial in nature, as in the case of investors, or qualitative in nature, as in the case of non-profit or social organizations. Success or failure is a relative assessment, as is the concept of gain or loss on the part of the stakeholders. The stakeholders, often referred to as the principles, give the right to manage the organization to agents, ostensibly qualified to do so, and who are rewarded accordingly, through the application of policies and rules that represent the principle's best interests. The process is generally known as governance, a word derived from the Latin verb "to steer." Agents are often highlevel or middle-level managers and administrators that derive short and long-term monetary gains that are directly related to the organization's success. There are as many forms of governance as there are organizations to control. Even though the words are similar, governance does not imply local, regional, or central government.

The principles of effective corporate governance are well-defined and usually implemented through "boards of directors" and other governing bodies. Governance is usually related to consistent management, cohesive policies, and effective decision rights. ${ }^{16}$ Information technology (IT) governance is generally regarded as a subset of corporate governance, as it relates to the operational management of IT systems. IT governance deals primarily with the connection between business focus and IT management and often involves the organization's IT application portfolio. ${ }^{17}$ IT governance is an important consideration in corporate governance because of the typically large budgets for IT infrastructure. Service governance is a subset of IT governance that assures the principals that the development and use of services are executed according to best practices.

Two important factors relate to service governance. The first factor involves the high-level of outsourcing of IT functionality and infrastructure. The main concern is the loss of control to an external service provider, and also the long-term loss of capability in critical areas of competence. The second factor is in the evolution to serviceoriented architecture for the development of business/enterprise applications. The synthesis of applications from components accessed over the Internet from external service providers constitutes a long-term dependency with which many principals are not comfortable. In this case, the principals may want to use service governance as a means of protecting the long-term interest and possibly the intellectual capital of the parent organization.

\section{QUICK SUMMARY}

The main objective of this paper is to present an overview of the dynamically changing boundary of the modern enterprise, based on a portfolio of services. The overview is summarized in the following entries.

1. There are three forces operating in the sphere of service processes. The first is the use of ICT as an enabler in providing revenue growth, efficiency, and effectiveness for traditional and enhanced services, as well as

\footnotetext{
${ }^{16}$ See the Wiki article on governance.

${ }^{17}$ See the Wiki article on IT governance.
} 
for conventional business processes. This subject is commonly referred to as information systems. The second is the consulting services domain that provides IT services to external organizations. The third is the use of ICT to manage information systems and services, which is a field of endeavor known as IT Services Management. Briefly said, it is the use of computers to manage the enterprise and also to manage itself.

2. The notion of service has its origin in ancient times and was understood to mean "one person doing something for another." With the advent of civilization and industrialization, the definition of service was implicitly extended to encompass "one person doing something for an organization," usually in the form of employment. At this stage, specialization and entrepreneurship kicked in with all of their rights and privileges resulting in what we now recognize as the service organization.

3. Information is a critical asset in the operation of an enterprise and in the everyday lives of individuals. In a figurative sense, information is the grease that allows the components to work together. IT is employed to handle the information needed to manage the operations of an enterprise and to aid in making effective decisions. Thus, IT is a service to the enterprise, regardless if that enterprise is concerned with production processes, service operations, government reporting, professional services, scientific services, technical services, or personal services.

4. There are several aspects of IT services that can vary between organizations. Examples are commonplace: computer operations, network management, hardware and software acquisition, system analysis and design, software design, software development, information systems integration, and call center and help desk operation and management. This is a representative set of tasks necessary for sustaining an IT services organization. You can do them yourself; you can have another business entity help you do them; or you can have a business entity do them for you. In the latter two cases, the business process is known as IT service outsourcing.

5. The service lifecycle consists of five important elements, listed as follows: Service Strategy, Service Design, Service Transition, Service Operation, and Continuous Improvement.

6. Service quality is a complex arrangement of client expectations, client education, business value, and business utility. It is elusive because clients usually cannot assess quality until after a service event has been completed. Service providers present quality as adherence to standard operating procedures. Service clients view service quality based on expectations and value creation.

7. Every year, businesses spend millions of dollars on their IT infrastructure consisting of hardware, system software, applications, networks, people, and other organizational assets. With "on demand" computing, they can plug into the wall, figuratively speaking, and only pay for the IT services they use. The concept is called utility computing that is accessed as most public utilities. We are going to name the utility computing concept as E-Services.

8. A business model is a representation of a business emphasizing its purpose, strategies, organization and operational practices, and capabilities. It typically covers the following: core capabilities, partner network, value proposition, customer base, distribution methods, cost structure, and revenue base.

9. A strategy has been defined as "A long term plan of action designed to achieve a particular goal," and governance as "The set of processes, customs, policies, laws, and institutions affecting the way an endeavor is directed, administered, or controlled."

10. A strategic asset is a resource that provides the basis for core competencies, economic benefit, and competitive advantage, thereby enabling a service business to provide distinctive service in the marketplace. Because services are labor intensive, investments in people, processes, knowledge, and infrastructure are directly analogous to investments in resources for production and distribution in capital intensive businesses.

11. The objective of service provisioning - regardless of whether the service involves people processing, possession processing, or information processing - is to provide value to customers through an intrinsic knowledge of customer needs obtained by preparation,, analysis, usage patterns, and the application of best practices. Within this perspective, a service may be alternately defined as a means of delivering value to customers by facilitating outcomes customers want to achieve without the ownership of specific costs and risks.

12. The objective of a service business is to assist in making resources available to the client as services, and in the process, creating value for both provider and client. The value of a service is determined by a client's expectation of service and the client's perception of the service that is experienced. Expectations are 
developed by word of mouth, personal needs, and past experience. The service that is delivered is a complex combination of five attributes: reliability, responsiveness, assurance, empathy, and tangibles.

\section{ACKNOWLEDGMENTS}

Thanks to William Dowling and Margaret Katzan for reading the manuscript.

\section{REFERENCES}

1. $\quad$ Carter, S., The New Language of Business, Upper Saddle River, NJ: IBM Press, 2007.

2. Cherbakov, L., et al, "Impact of service orientation at the business level", IBM Systems Journal, Vol. 44, No. 4, 2005.

3. Clark, J., Everything you ever wanted to know about ITIL $®$ in less than one thousand words! Connect Sphere Limited, www.connectsphere.com, 2007.

4. Collier, D. and J. Evans, Operations Management: Goods, Services, and Value Chains, Mason OH: Thomson Higher Education, 2007.

5. Fitzsimmons, J. and M. Fitzsimmons, Service Management: Operations, Strategy, Information Technology (6 ${ }^{\text {th }}$ Edition), New York: McGraw-Hill/Irwin, 2008.

6. Fitzsimmons, J.A. and M.J. Fitzsimmons, Service Management: Operations, Strategy, Information Technology $\left(6^{\text {th }}\right.$ Edition), New York: McGraw-Hill/Irwin, 2008.

7. Ganek, A. and K. Kloeckner, “An overview of IBM Service Management," IBM Systems Journal, Vol. 46, No. 3, 2007.

8. Hagel, J. and J.S. Brown, From Push to Pull: Emerging Models for Mobilizing Resources, www.edgeperspectives.com, 2007.

9. Heizer, J. and B. Render, Operations Management ( $\left(^{\text {th }}\right.$ Edition), Upper Saddle River, NJ: Pearson PrenticeHall, 2006.

10. Hurwitz, J., Bloor, R., Baroudi, C., and M. Kaufman, Service Oriented Architecture for Dummies, Hoboken, NJ: Wiley Publishing, Inc., 2007.

11. ITIL, Service Strategy, London: The Stationary Office, 2007.

12. itSMF, An Introductory Overview of ITIL® V3, itSMF Ltd,, 2007.

13. Katzan, H., A View of Services Science, Southeast Decision Science Institute, Savannah, GA, February 2123, 2007.

14. Katzan, H., "Event Differentiation in Service Science," Journal of Business and Economics Research, Volume 6, Number 5 (May 2008), pp 141-151.

15. Katzan, H., Service Science: Concepts, Technology, Management (in press), 2008.

16. Krafzig, D., Banke, K., and D. Slama, Enterprise SOA: Service-Oriented Architecture Best Practices, Upper Saddle River, NJ: Prentice Hall, 2005.

17. Metters, R., King-Metters, K., Pullman, M., and S Walton, Successful Service Operations Management (2e), Boston: Thomson Course Technology, 2006.

18. Microsoft Operations Framework (MOF), TechNet publication, Microsoft Corporation, www.microsoft.com/MOF, 2008.

19. Nichols, M., "Quality Tools in a Service Environment,“www.ASQ.org, 2007.

20. Rappa, M.A., "The utility business model and the future of computing services," IBM Systems Journal, Vol. 43, No. 1, 2004.

21. Wikipedia, Business Models, www.wikipedia.com, 2008.

22. Wikipedia, Corporate Governance, www.wikipedia.com, 2008.

23. Wikipedia, Governance, www.wikipedia.com, 2008.

24. Wikipedia, Information Technology Governance, www.wikipedia.com, 2008.

25. Wikipedia, Software as a Service, www.wikipedia.com, 2008.

26. Wikipedia, Strategy, www.wikipedia.com, 2008.

27. Wikipedia, Thinking Processes, www.wikipedia.com, 2008.

28. Woods, D. and T. Mattern, Enterprise SOA: Designing IT for Business Innovation, Sebastopol, CA:

O’Reilly Media Inc., 2006. 